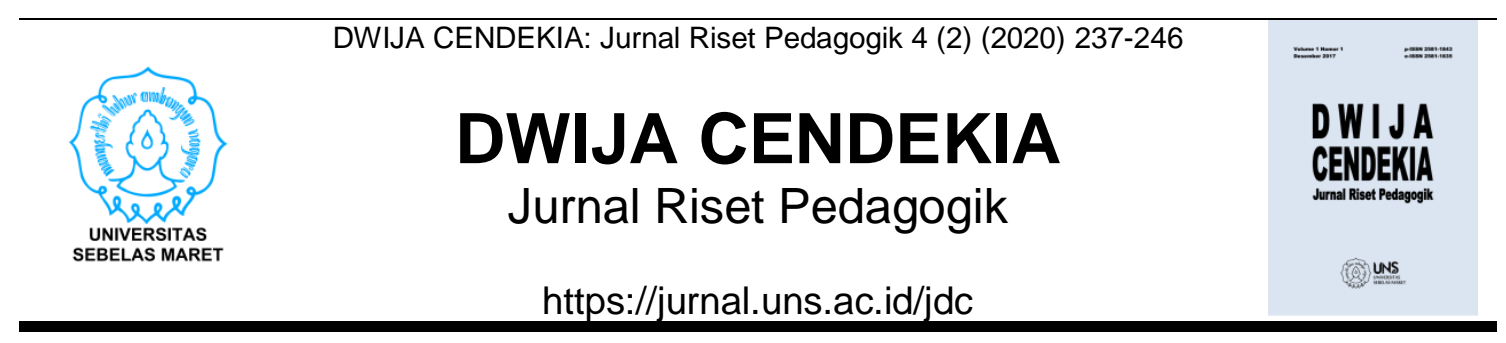

\title{
Implementasi Aplikasi Games pada Mata Kuliah Pengembangan Minat Baca dan Tulis
}

\section{Laily Nurmalia, Lutfi, Hernita Urmadi}

Universitas Muhammadiyah Jakarta

laily.nurmalia@gmail.com

\section{Sejarah Artikel}

diterima 28 Oktober 2020

\begin{abstract}
Technology-based learning media, one of which is the kahoot game application, is widely used by teachers and students who are useful and used by all levels from Elementary School to Higher Education, especially when it is currently being hit by the Covid-19 pandemic. In this study, the aim of this research is to find out how to implement the games application in the Reading and Writing Interest Development course. The method used is qualitative. The data collected through observation and interviews with the object of research, namely the 6th semester students of PGSD UMJ. The results showed that the Kahoot games application was effectively used by students in reading and writing interest development courses.

Keywords: games application, interest in reading and writing
\end{abstract}

\begin{abstract}
Abstrak
Media pembelajaran berbasis teknologi salah satunya aplikasi game kahoot banyak digunakan pengajar dan peserta didik yang bermanfaat serta digunakan oleh seluruh jenjang dari Sekolah Dasar hingga Perguruan Tinggi terutama saat ini yang sedang dilanda pandemic covid-19. Pada penelitian ini bertujuan untuk mengetahui bagaimana pengimplementasi aplikasi games pada mata kuliah Pengembangan Minat Baca dan Tulis. Metode yang digunakan adalah kualitatif. Data yang dikumpulkan melalui observasi dan wawancara dengan objek penelitian yakni mahasiswa semester 6 PGSD UMJ. Hasil penelitian menyatakan bahwa aplikasi games Kahoot efektif digunakan oleh mahasiswa pada mata kuliah pengembangan minat baca dan tulis.

Kata kunci: Aplikasi Games, Minat Baca dan Tulis
\end{abstract}




\section{PENDAHULUAN}

Pada zaman globalisasi saat ini dibutuhkan teknologi informasi tidak bisa lewatkan serta menjadi kebutuhan yang vital. Pengendalian teknologi informasi menjadi suatu "gaya hidup" untuk sebagian besar masyarakat lebih khusus para pemuda. Bersama tatanan dunia yang telah melirik dari ranah konvensional kepada ranah digital, kerena perkembangan teknologi informasi serta komunikasi telah melebarkan sayapnya ke dunia pendidikan (khabidin, 2019). Untuk seorang pendidik, kemahiran serta pengetahuan teknologi (technological knowledge) ialah kompetensi wajib dikuasai untuk mendukung peningkatan proses pembelajaran pada peserta didik. Sementara bagi peserta didik, penguasaan teknologi bisa menunjang proses berpikir serta penguasaan Ilmu Pengetahuan. Perkembangan media pembelajaran pada Perguruan Tinggi perlahan diikuti oleh perubahan-perubahan bertujuan untuk memudahkan pembelajaran.

Misalnya keberadaan papan tulis sudah bisa dikomplementer pada LCD proyektor, sehingga dosen/pengajar tidak harus menuliskan materi didepan kelas. Keadaan ini disebutkan sebagai pembelajaran berbasis teknologi. Kegunaan teknologi untuk mendukung pembelajaran ialah suatu hal yang lazim serta akan menghasilkan dampak positif. Pembaharuanpembaharuan teknologi tidak berhenti sampai disitu saja. Perkembangan ilmu pengetahuan pada gilirannya diikuti perkembangan teknologi yang menuju dan memikirkan masa depan. Mewujudkan pendidikan berkualitas erat kaitannya pada pendidik yang berkualitas. Tahun 2009, sebuah laporan dengan judul "Learning for the 21st Century" mempublikasikan "Framework for 21st Century Learning" (Heflebower, 2012) menerangkan empat kompotensi pada bidang yang dikuasai oleh peserta didik yaitu sebagai berikut "1) core subject and 21st century themes, 2) learning and innovative skills, 3) information, media and technology skills and 4) life and career skills". Menurut pernyataan di atas dapat lihat bahwa penggunaan teknologi pada pembelajaran harus diadaptasi dengan tema saat ini yaitu abad 21. Pada abad 21 memiliki fenomena adalah berbasis digital, pendidikan pun harus perlahan beralih ke aspek digital (digitalisasi).

Relevansi di lapangan, bersifat konvensional di perkuliahanperkuliahan yang ada saat ini. Sebagian tenaga pendidik/dosen masih nyaman pada proses pembelajaran konvensional sehingga inovasi berpikir dalam pembelajaran yang konvensional kepada digitalisasi harus dilakukan secara cepat. Salah satunya di mata kuliah Pengembangan Minat Baca dan Tulis pada jurusan Pendidikan Guru Sekolah Dasar sebagai mata kuliah yang harus ditempuh oleh mahasiswa di perguruan tinggi pada fakultas pendidikan. Persoalan yang ada adalah pada pembelajaran pada mahasiswa dirasa bosan terhadap materi disampaikan dosen. Selain itu, kurangnnya interaksi pada proses pembelajaran di kelas. Hal itu ditunjukkan pada terjadinya komunikasi satu arah adalah Dosen ke Mahasiswa saja. Sehingga membutuhkan cara/metode ataupun media berbasis teknologi yang bisa meningkatkan kualitas pembelajaran di kelas. 
Menurut Arsyad, salah satu media pembelajaran berbasis teknologi yang dapat meningkatkan kualitas pembelajaran yakni aplikasi games Kahoot (Ningrum, 2018). Terutama saat kondisi sekarang sedang dilanda pandemic covid-19, dimana seluruh pelajar dari tingkat PAUD hingga Perguruan Tinggi harus belajar dirumah masing-masing tidak lagi belajar di sekolah. Pengajar hanya dapat menjelaskan dan memberikan tugas melalui media teknologi. Sehingga media pembelajaran berbasis teknologi yakni aplikasi games Kahoot sangat cocok digunakan untuk belajar di rumah masing-masing.

Pemanfaatan Kahoot sebagai media pembelajaran berharap dapat menjadi alternatif untuk dosen serta mahasiswa dalam membangun suasana perkuliahan yang menarik dan tidak bosan untuk diikuti mahasiswa. Pada awalnya perkuliahan cenderung kaku serta monoton akan beralih ke suasana kelas yang riang dengan pola Kahoot tersebut. Media Kahoot Dapat dimanfaatkan sejalan pada era digitalisasi pada saat ini di Perguruan Tinggi baik PTN dan PTS. karenannya peneliti tertarik membuat penelitian tentang Kahoot untuk media pada pembelajaran serta efektivitas oleh penggunaan media tersebut. Bagaimana pengimplementasian media pembelajaran aplikasi games Kahoot sebagai alat pembelajaran Pengembangan Minat Baca dan tulis pada mahasiswa PGSD FIP UMJ.

Menurut John Renold Siregar (Siregar, 2014) media pembelajaran merupakan salah satu komponen penting dan tidak terpisahkan dari keseluruhan proses pembelajaran dalam semua program dan jenjang, sehingga keterampilan untuk mengembangkan dan memanfaatkan media pembelajaran amat dibutuhkan oleh seorang guru yang professional. Menurut Munadi (Munadi, 2008) fungsi utama media pembelajaran adalah sebagai sumber belajar. Adapun tujuan media pembelajaran adalah mengefektifkan proses komunikasi pembelajaran sehingga tercapai tujuan yang diinginkan atau adanya perubahan tingkah laku. Menurut Azhar (Azhar, 2007) pemakaian media dalam pembelajaran banyak memberikan manfaat pada proses pembelajaran. Dilihat dari manfaat, pemakaian media pembelajaran dalam proses belajar mengajar dapat membangkitkan keinginan dan minat yang baru, membangkitkan motivasi dan rangsangan kegiatan belajar dan bahkan membawa pengaruh psikologis terhadap siswa.

Salah satu perubahan teknologi yang bisa diimplementasikan pada proses pembelajaran yaitu penggunaan platform Kahoot!. Kahoot! adalah web tool yang menyediakan menyediakan permainan daring berkonsep pendidikan (Irwan, 2019) . "Kahoot!" merupakan website edukatif yang pada awalnya diinisiasi oleh Johan Brand, Jamie Brooker dan Morten Versvik dalam sebuah joint project dengan Norwegian University of Technology and Science pada Maret 2013 (Rafnis, 2018)

Kahoot merupakan Platform gratis ini meringankan tugas dosen untuk membuat kuis/ujian tidak lagi harus mendikte di kelas serta mahasiswa juga tidak harus menjawab pada lembar jawaban seperti biasanya. Dosen hanya menampilkan soal/materi ujian dengan laptop serta ditampilkan menggunakan layar LCD, sementara itu mahasiswa membuat jawaban via telepon genggam perindividu saat kuis berlangsung. laman Kahoot! akan menampilkan 
langsung isian yang mereka jawab secara benar atau salah disesuaikan dengan soal serta skor tertinggi dapat dilihat pada peserta yang menjawab paling cepat serta benar. Hal ini agar menunjang daya kompetisi mahasiswa dalam proses menjawab pertanyaan yang tampilkan dosen. Ada prasyarat dapat media kuis interaktif Kahoot! agar dilakukan ialah ketersediaan aliran listrik, piranti laptop, infocus, telepon genggam, dan ketersediaan koneksi internet itu yang paling penting.

Kahoot dapat diartikan sebagai media pembelajaran interaktif karena kahoot dapat digunakan dalam kegiatan belajar mengajar seperti mengadalan pre-test, post-test, latihan soal, penguatan materi, remedial, pengayaan dan sebagainya. Salah satu syarat untuk membuat kahoot adalah memiliki akun gmail atau akun lainnya. Kahoot memiliki empat fitur yaitu game, kuis, diskusi dan survey. Serta ada bukti kuat yang menunjukkan hubungan anatara bermain game dan peningkatan motivasi, semakin banyak game pembelajaran bermunculan dan menjanjikan bantuan untuk belajar bahasa (Piskorz, 2016). Untuk game, bisa dibuat jenis pertanyaan dan menentukan jawabannya serta waktu yang digunakan untuk menjawab pertanyaan tersebut. Uniknya, jawaban nantinya akan diwakili oleh gambar dan warna. Peserta diminta untuk memilih warna atau gambar yang mewakili jawaban yang tepat. Selain mencari jawaban yang tepat. Peserta harus memastikan tidak salah sentuh (klik) ketika memilih jawaban. "Kahoot!" memiliki dua alamat website yang berbeda yaitu https://kahoot.com/ untuk pengajar dan https://kahoot.it/ untuk pembelajar. (Rafnis, 2018) Kahoot juga sudah tersedia dalam bentuk aplikasi di handphone yang bisa di download dengan bebas biaya di playstore. Kahoot dapat diakses dan digunakan secara gratis, termasuk semua fitur-fitur yang ada di dalamnya. Platform Kahoot dapat digunakan untuk beberapa bentuk asesmen diantaranya kuis online, survei, dan diskusi dimana ketiganya memiliki cara yang bermacam-macam untuk dimainkan. Diperlukan koneksi internet untuk dapat memainkan game ini. Kahoot dapat dimainkan secara individu, meskipun demikian yang menjadi desain utamanya adalah permainan secara berkelompok (Muzakki, Aprilia Riyana dan Muahmmad Alie, 2019). Aplikasi Kahoot sebagai platform teknologi pembelajaran mengkombinasikan pengalaman evaluasi pembelajaran dengan game interaktif dan dilengkapi system monitoring aktifitas para peserta didik (Santos, M. Correia and $R, 2017$ ) . Inovasi platform Kahoot ini juga mampu membantu aktifitas evaluasi pembelajaran menjadi menarik, interaktif, kondusif dan mudah dalam memonitoring hasil belajar (Dewi, 2018). Dan juga teknologi informasi dan komunikasi atau TIK pada zaman sekarang sangat dibutuhkan oleh setiap masyarakat baik itu orang dewasa maupun anakanak (Dwi Nugraheny, 2019)

Kahoot juga memiliki kelebihan sebagai media pembelajaran yakni suasana kelas dapat lebih menyenangkan, anak-anak dilatik untuk menggunakan teknologi sebagai media untuk belajar, dan anak-anak di latih kemampuan motoriknya dalam pengoperasian Kahoot. Selain kelebihan, Kahoot juga memiliki kelemahan sebagai media pembelajaran yaitu tidak semua guru yang update dengan teknologi, fasilitas sekolah kurang memadai, anak-anak 
mudah terkecoh untuk membuka hal lainnya, terbatarnya jam pertemuan di kelas, tidak semua guru memiliki waktu untuk mengatur menyusun rancangan pembelajaran dengan Kahoot.

Sehingga dosen dituntut untuk dapat menggunakan teknologi salah satunya dapat menggunakan media pembelajaran berbasis teknologi yaitu Kahoot. Kahoot dapat bermanfaat dalam proses belajar mengajar di kelas. Oleh sebab itu, menurut peneliti diperlukan tindakan sebuah penelitian yang meneliti tentang penggunaan aplikasi games Kahoot digunakan oleh dosen. Sehingga peneliti melakukan penelitian tentang Implementasi Aplikasi Games Pada Mata Kuliah Pengembangan Minat Baca Dan Tulis PGSD UMJ.

Pada penelitian ini memiliki tujuan yakni untuk mengetahui bagaimana pengimplementasi aplikasi games pada mata kuliah Pengembangan Minat Baca dan Tulis. Rumusan masalah pada penelitian yaitu bagaimana implementasi aplikasi games kahoot pada mata kuliah pengembangan minat baca dan tulis.

\section{METODE}

Metode penelitian yang menggunakan di penelitian ini ialah pendekatan kualitatif. Metode penelitian menggunakan adalah metode observasi dan wawancara. Prosedur penelitian ini adalah melakukan observasi dan wawancara terlebih dahulu ke mahasiswa apakah mengetahui apa itu kahoot dan apakah pernah menggunakan kahoot. Kemudian peneliti ke setiap kelas memberikan penjelasan tentang aplikasi games Kahoot, mendemonstrasikan penggunaan aplikasi games Kahoot, mahasiswa diberikan instrument berupa angket, dan terakhir melakukan evaluasi. Prosedur analisis data yang digunakan adalah secara deskriptif.

Waktu pelaksanaan penelitian dari bulan April 2020 hingga Juni 2020. Tempat penelitian di Universitas
Muhammadiyah Jakarta, Fakultas Ilmu Pendidikan, prodi Pendidikan Guru Sekolah Dasar, semester enam. Populasi penelitian ini sebanyak 185 mahasiswa yang terdiri dari lima kelas yakni kelas A-SD, B-SD, C-SD, D-SD, dan E-SD. Sampel yang diambil secara acak yang berjumlah 67 mahasiswa.

Analisis data yang digunakan adalah kualitatif deskriptif. Kualitatif deskriptif bertujuan untuk mendeskripsikan perilakuk orang, peristiwa lapangan, serta kegiatankegiatan tertentu secara terperinci dan mendalam. Adapun yang dimaksud dengan penelitian deskriptif yaitu suatu penelitian sekedar untuk menggambarkan suatu variable yang berkenaan dengan masalah yang diteliti tanpa mempersoalkan hubungan antar variabel (Faisal, 1992).

\section{PEMBAHASAN}

Pada penelitian ini yang dilakukan saat pertama kali yaitu melakukan observasi ke semua kelas yakni kelas A-SD, B-SD, C-SD, D-SD, dan E-SD. Survei berupa menanyakan langsung kepada mahasiswa apakah para mahasiswa mengetahui apa itu aplikasi games kahoot sebagai media teknologi pembelajaran? Apakah mahasiswa pernah menggunakan 
media teknologi pembelajaran berupa aplikasi games kahoot saat perkulihan berlangsung? Dan jawaban yang diberikan hampir $90 \%$ mahasiswa tidak mengetahui apa itu aplikasi games kahoot dan tidak pernah menggunakan media teknologi pembelajaran berupa aplikasi games kahoot saat perkuliahan berlangsung.

Setelah kami mengetahui hasil observasi tersebut peneliti ingin memberikan sosialisasi secara langsung dengan mahasiswa namun dikarenakan terdapat pandemic covid19 kami tidak diperkenankan untuk berkumpul, bertatap muka langsung ataupun datang ke kampus, sehingga peneliti memberikan sosialisasi melalui aplikasi zoom atau bisa dikatakan bertatap muka secara online. Pemberikan sosialisai penjelasan mengenai aplikasi games kahoot agar para mahasiswa dapat memahami terlebih dahulu apa itu aplikasi games kahoot. Setelah penjelasan peneliti melakukan demonstrasi cara penggunaan aplikasi kahoot, dari cara log in akun kahoot, cara membuat soal, cara membuat jawaban hingga cara log out dari aplikasi games kahoot. Setelah selesai di demonstrasikan kemudian di praktekan langsung oleh para mahasiswa dengan menggunakan handphone atau laptop masing-masing.

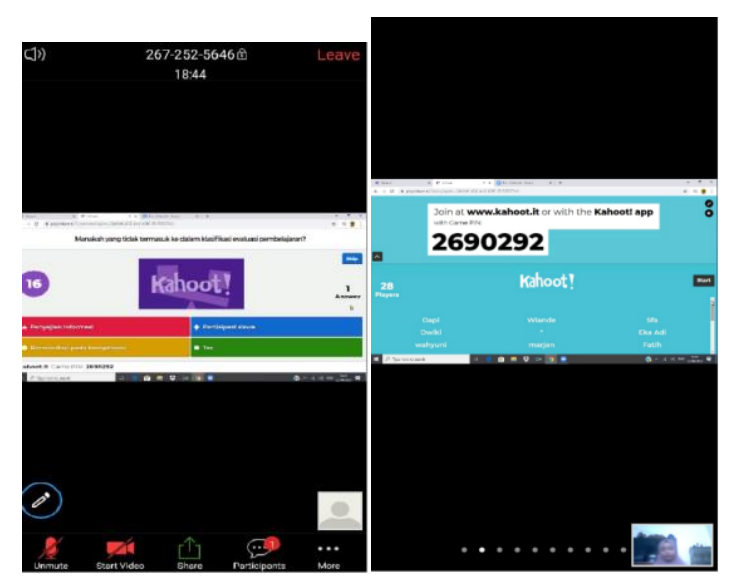

Gambar 1 Saat menerapkan kahoot via aplikasi zoom

Instagram dikarenakan tidak semua

Gambar di atas merupakan saat peneliti melakukan sosialisai dan menerapkan aplikasi games Kahoot via aplikasi zoom. Selain aplikasi zoom peneliti juga melakukan sosialisasi mahasiswa dapat mengakses zoom dengan baik sehingga beberapa mahasiswa menganjurkan dengan menggunakan aplikasi live instragram. menggunakan aplikasi live Instagram. Peneliti menggunakan aplikasi live 

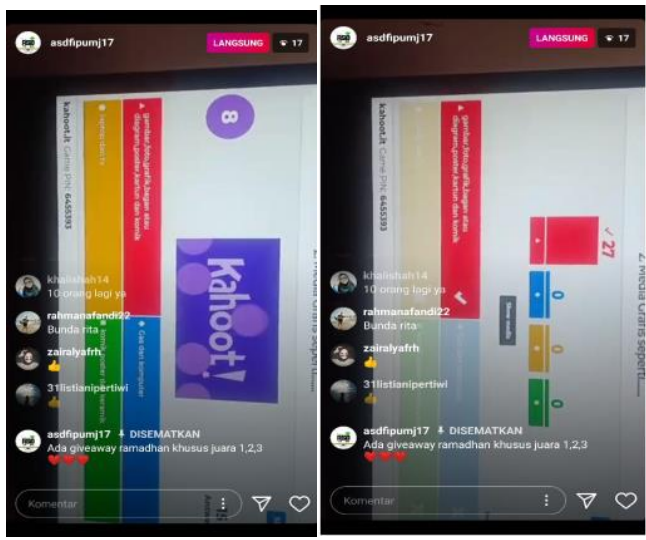

\section{Gambar 2. Saat menerapkan kahoot via aplikasi live Instagram} kepada mahasiswa satu per satu maka

Gambar di atas merupakan saat menerapkan aplikasi games kahoot via aplikasi live Instagram. Setelah setelah menerapkan aplikasi games kahoot para mahasiswa diberikan instrument berupa angket. Di karenakan peneliti peneliti membuat angket dalam bentuk google form sehingga mereka dapat mengisi angket tersebut melalui handphone masing-masing. Berikut ini hasil angket yang telah diberikan kepada pada mahasiswa: tidak dapat memberikan kertas angket

Tabel 1. Hasil angket

\begin{tabular}{clccc}
\hline No & \multicolumn{1}{c}{ Pernyataan } & lya & Tidak & Total \\
\hline 1. & Apakah anda menyukai aplikasi games kahoot? & 60 & 7 & 67 \\
\hline 2. & $\begin{array}{l}\text { Apakah menurut anda aplikasi games kahoot cocok untuk mata } \\
\text { kuliah pengembangan minat baca dan tulis? }\end{array}$ & 65 & 2 & 67 \\
\hline 3. & Apakah aplikasi games kahoot mudah digunakan? & 62 & 5 & 67 \\
\hline 4. & Apakah aplikasi kahoot membuat Anda lebih memahami materi? & 67 & 0 & 67 \\
\hline 5. & $\begin{array}{l}\text { Apakah Anda merasa tidak nyaman menggunakan aplikasi games } \\
\text { kahoot? }\end{array}$ & 3 & 64 & 67 \\
\hline 6. & $\begin{array}{l}\text { Apakah aplikasi games kahoot dapat menambah motivasi belajar } \\
\text { Anda? }\end{array}$ & 64 & 3 & 67 \\
\hline 7. & $\begin{array}{l}\text { Apakah aplikasi games kahoot membuat Anda jenuh dalam belajar? } \\
\text { 8. }\end{array}$ & 0 & 67 & 67 \\
\hline $\begin{array}{l}\text { Apakah aplikasi games kahoot mempengaruhi diri Anda dalam } \\
\text { belajar? }\end{array}$ & 65 & 2 & 67 \\
\hline 9. & $\begin{array}{l}\text { Apakah aplikasi games kahoot dapat mengembangkan } \\
\text { pembelajaran minat baca dan tulis? }\end{array}$ & 66 & 67 \\
\hline 10. & $\begin{array}{l}\text { Apakah aplikasi games kahoot membuat Anda dapat berinovasi } \\
\text { dalam mata kuliah pengembangan minat baca dan tulis? }\end{array}$ & 63 & 4 & 67 \\
\hline 11. & $\begin{array}{l}\text { Apakah aplikasi games kahoot dapat menumbuhkan kreatifitas } \\
\text { dalam mata kuliah minat baca dan tulis? }\end{array}$ & 61 & 67 \\
\hline 12. & $\begin{array}{l}\text { Apakah aplikasi games kahoot membuat Anda giat menambah dan } \\
\text { mengembangkan baca dan tulis? }\end{array}$ & 62 & 67 \\
\hline
\end{tabular}




\begin{tabular}{clccc}
\hline 13. & $\begin{array}{l}\text { Apakah aplikasi games kahoot menambah wawasan untuk } \\
\text { mengembangkan mata kuliah pengembangan minat baca dan } \\
\text { tulis? }\end{array}$ & 67 & 07 & 67 \\
\hline 14. & $\begin{array}{l}\text { Apakah aplikasi games kahoot mudah untuk diajarkan kepada } \\
\text { siswa untuk pengembangan minat baca dan tulis? }\end{array}$ & 60 & 7 & 67 \\
\hline 15. & $\begin{array}{l}\text { Apakah aplikasi games kahoot memungkinkan untuk diaplikasikan } \\
\text { pada siswa SD? }\end{array}$ & 61 & 6 & 67
\end{tabular}

Berdasarkan hasil penelitian

minat baca dan tulis di PGSD UMJ implementasi aplikasi games kahoot dapat dibuat grafik seperti dibawah ini: pada mata kuliah pengembangan

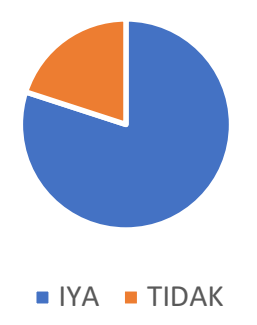

\section{Gambar 3. Presentase Hasil Angket}

Dari gambar di atas menunjukan bahwa presentase hasil angket yang sudah diberikan kepada mahasiswa semester 6 PGSD UMJ adalah pada gambar berwarna biru hasilnya $80 \%$ mahasiswa menjawab iya dan pada gambar berwarna oranye hasilnya $20 \%$ mahasiswa menjawab tidak. Hasil tersebut menunjukkan bahwa aplikasi games kahoot dapat digunakan dan telah efektif digunakan oleh para mahasiswa di mata kuliah pengembangan minat baca dan tulis PGSD UMJ.

\section{SIMPULAN}

Hasil data yang didapat Muhammadiyah Jakarta. Namun mendapatkan hasilnya yakni $80 \%$ terdapat kendala yakni saat sosialisasi menyakatan iya dan $20 \%$ menyatakan dan demonstrasi tidak dapat tidak. Berdasarkan hasil data penelitian membantu para mahasiswa secara tersebut menyatakan bahwa aplikasi langsung hanya dapat membantu games kahoot dapat digunakan dan secara online via zoom atau live telah efektif di gunakan pada mata Instagram saja. Dan juga terdapat kuliah pengembangan minat baca dan kendala koneksi sinyal internet yang tulis pada jurusan Pendidikan Guru Sekolah Dasar Universitas buruk pada beberapa peserta. 


\section{DAFTAR PUSTAKA}

Azhar. (2007). Media Pembelajaran. Jakarta: Raja Grafindo Persada.

Dewi, K. C. (2018). Pengembangan Alat Evaluasi Menggunakan Aplikasi Kahoot Pada Pembelajaran Matematika Kelas $X$.

Dwi Nugraheny, H. W. (2019). Pendampingan Pengenalan Metode Pengetikan Cepat Menggunakan Microsoft Word Bagi Siswa Kelas 5 SD IT Salsabila Al Muthi'in Yogyakarta. Jurnal Pengabdian Masyarakat Bidang Teknologi, KACANEGARA, 2 Nomor 1, 21.

Faisal, S. (1992). Format-format Penelitian Sosial. Jakarta: Rajawali Press.

Heflebower, M. (2012). Learning for the 21st Century "Framework for 21st Century Learning".

Irwan. (2019). Implementasi Kahoot! Sebagai Inovasi Pembelajaran. Padang Jurnal Civic Education Vol.2 No.1.

khabidin. (2019). Efektivitas Penerapan Aplikasi Kahoot dalam Mengkondisikan Kelas Pada Mata Pelajaran Pendidikan Agama Islam di SMPN 1 Pagetan Kabupaten Banjarnegara. Universitas Islam Indonesia.
Munadi. (2008). Media Pembelajaran. Ciputat: Gaung Persada (GP) Press.

Muzakki, Aprilia Riyana dan Muahmmad Alie. (2019). Implementasi Kahoot Sebagai Media Pembelajaran Berbasis Digital Game Based Learning Dalam Menghadapi Era Revolusi Industri 4.0. Prosiding Seminar Nasional (hal. 23). Kudus: ISBN: 978-602-118099-0.

Ningrum, G. D. (2018, april 1). Studi Penerapan Media Kuis Interaktif Berbasis Game Edukasi Kahoot Terhadap Hasil Belajar Siswa. VOX Edukasi Jurnal IImiah IImu Pendidikan, 9(1), 1-81. doi:http://jurnal.stkippersada.ac. id/jurnal/index.php/VOX/article/ view/32/29

Piskorz, E. Z. (2016). Kahoot It Or Not? Can Games Be Motivating In Learning Grammar? The Journal Of Teaching English With Technology(3), 17-36. Diambil kembali dari https://www.ceeol.com/search/a rticle-detail?id=420768

Rafnis. (2018). Pemanfaatan Platform Kahoot Sebagai Media Pembelajaran Interaktif. Jurnal IImiah Teknologi Pendidikan, Vol. 6 No. 2(ISSN: 2126-7759), 2. 
Santos, M. Correia and R. (2017). Siregar, J. R. (2014). Peningkatan Game Based Learning: The Use of Kahoot in Teacher Education. Keterampilan Guru International Symposium on Menggunakan Media Computer In Education (SIIE) Pembelajaran Melalui Lesson Study Di SMAN 04 Merlung Kabupaten Tanjung Jabung Barat. Jurnal Pendidikan dan Kepengawasan, Vol 1. No. 1. 